\title{
A RETÓRICA DA PERSUASÃO EM SAIKAKU ${ }^{1}$
}

Madalena N. Hashimoto Cordaro

RESUMO: Centralizando-se em tradução de trecho inicial de Nanshoku Ôkagami ( $O$ Grande Espelho do Amor de Homens), analisam-se recursos poéticos da tradição do período Heian utilizados por Ihara Saikaku no Primeiro Período Edo (1600-1750) no sentido de uma construção de um discurso persuasivo do narrador, especialmente através de mitate e mono-awase.

ABSTRACT: Centralized in Nanshoku Ôkagami (The Big Mirror of Male Love's) inicial text translation, Heian period poetic tropos used by Ihara Saikaku in the First Edo Period (1600-1750) are analysed in the sense of a narrator's persuasive discourse construction, specially through mitate and mono-awase.

PALAVRAS-CHAVE: literatura do período Edo, Ihara Saikaku, escritos kôshoku, metáfora, paródia, ironia, comparação.

KEYWORDS: Edo period literature, Ihara Saikaku, kôshoku writings, metaphor, parody, irony, comparison.

1. Ihara Saikaku (1642-1693) foi o mais apreciado escritor da era Genroku (1688-1703). Nascido em Ôsaka, sob o nome Hirayama Tôgo, supõe-se ter sido proveniente de família abastada de comerciantes. Prolífico por natureza, Saikaku foi primeiramente poeta em haikai-no-renga, discípulo da escola Danrin liderada por Nishiyama Sôin (1605-1682), tendo inventado a "competição arco-e-flecha" (yakazu) baseada na velocidade em compor versos. Sua prosa poética se deve à prática do haikai veloz: a tessitura de ritmos, construções de imagens e recursos poéticos (jogos de homófonos ou ressonâncias, palavrastravesseiro, convenções sazonais) serve a narrativas de amor e usos-e-costumes de citadinos e samurais, no gênero ukiyo-zôshi. 
Por volta de 1686, quando Uma Mulher que se Deu ao Amor ${ }^{2}$ é publicado, Hishikawa Moronobu ${ }^{3}$ já havia desenhado muitos livros-pinturas (ehon) eróticos, e o viajante Saikaku, conhecendo suas obras, a elas se refere em suas narrativas do mundo flutuante, ukiyo-zôshi, atualizando seu leitor nas artes do momento, ligando-as às pinturas ukiyo-e, tanto em sua denominação enquanto gênero quanto nas tópicas tratadas, e, ainda, na retomada a convenções do período Heian.

Se escritos sobre o amor são abundantes em Heian, uma outra camada se superpõe nas obras kôshoku-bon, escritos sobre o amor do período Edo: o amor físico vai, com a introdução dos kiki, "instrumentos estranhos" do exterior (via Deshima, ilha artificialmente construída para comerciantes holandeses em Nagasaki) ${ }^{4}$, ser focalizado em

2. Kôshoku Ichidai Onna, editada em 1686, narra em primeira pessoa episódios da vida de uma mulher, em cuja vida amorosa vê-se, pela primeira vez, uma ênfase, segundo alguns estudiosos, na "depravação dos sentidos", que acaba desprovendo a heroína de posição social importante: primeiramente é dama de companhia no palácio imperial, depois, adotada em rica família provincial na Capital, mais tarde, escolhida para ser esposa secundária de daimio e gerar-lhe filhos. Decai para yûjo tayû em Shimabara, depois para yûjo tenjin, a seguir para yûjo tsubone; passa a ser concubina de um "monge lascivo"; torna-se agenciadora de mulheres, trabalha em oficinas de citadinos, em casas de chá e de banho. Enfim, após outras ocupações, termina como yobi-onna, "mulher-que-chama", puxando as mangas de homens que passam pelas ruas. A protagonista é, segundo alguns, uma "escrava do sexo" que, em seu gozo, juntamente com sua situação de mulher sozinha (numa época em que a mulher está abaixo de todas as categorias sociais reconhecidas), termina a vida envergonhada, arrependida e cheia de remorsos ao perceber, num templo, que, na longa jornada de sua vida, tivera mais de dez mil homens e noventa e cinco abortos. Também relacionada com uma obra do passado, a vida de Ono-no Komachi, mulher bonita famosa do período Heian, Saikaku utiliza ainda outras fontes, como catálogos críticos dos áreas-de-prazeres e das yûjo, e o formato de confissões arrependidas, zange, apreciado nos séculos anteriores, eivados de visão budista. Kôshoku Ichidai Onna tem paralelismos com Kôshoku Ichidai Otoko que não se restringem apenas ao título: ichidai foi interpretado durante muito tempo como uma vida, duração de uma vida, mas pode ser lido também como uma geração, um homem e uma mulher em apenas uma geração, sem família, quer dizer, sem descendência; uma vida que apenas frui sem frutificar.

3. Embora não se tenha muitas informações sobre sua vida, sabe-se que sua família fabricava e negociava com tecidos tingidos e brocados, principalmente a famílias e templos abastados da pequena vila pesqueira de Hoda, província de Awa, atual Chiba, e que recebeu treinamento não somente nos negócios da família mas também na pintura Tosa e Kanô, quando se põe a caminho da cidade de Edo. Através de uma exaustiva pesquisa, Hayashi Yoshikazu conclui que Moronobu morre no ano quatro da era Shotoku (1694), pois em sua terra natal, no templo familiar dos Moronobu, Rinkaizan Betsugan-in, um grande sino é encontrado com a seguinte inscrição: "Contribuição de Hishikawa Kichibei-no-Jo Fujiwara Moronobu Nyudo Yuchiku num dia auspicioso no sexto mês do ano 7 da era Genroku, ano do Cão Kinoe", contando possivelmente com setenta e sete anos, o que faria de 1618 sua provável data de nascimento. Depois de se mudar para Edo, Moronobu junta-se aos muitos "pintores-das-cidades", machi-eshi, sendo patrocinado por comerciantes. Não estando ligado a nenhuma família específica de pintura, os pintores-das-cidades são importantes produtores de imagens de usos-e-costumes dos chônin, em geral anônimos. Moronobu é o primeiro nome conhecido, embora se conjecture a existência de outros artistas que trabalhassem na mesma área, inclusive na xilogravura. Assim como ele, todos os artistas do período inicial de ukiyo-e se denominavam yamato-eshi, "pintor de yamato", nihon-eshi, "pintor do Japão", waga-shi, "profissional de pinturas japonesas".

4. Kiki, instrumentos estranhos, são importados da Holanda: telescópios, microscópios, óculos, prismas, caleidoscópios, geradores de eletricidade estática (erekiteru), utensílios de vidro, projetores, candelabros, relógios, brinquedos, canivetes, caixas de espiar (nozoki-megane), tesouras, vinho, doces, fauna e flora, livros. Timon Screech, in The Western Scientific Gaze and Popular Imagery in Later Edo Japan 
minúcias através de lentes de aumento, principalmente no Segundo Período Edo (17501868), como se vê já em Um Homem que se Deu ao Amor ${ }^{5}$, quando a personagem Yonosuke, ainda menino, espia uma servente a se banhar, com um telescópio, do alto do telhado. O procedimento retoma famoso recurso amoroso da era Heian: kaima-mi, "ver através de fendas, espiar"

A compreensão póstuma do termo kôshoku como sinônimo de "pornografia" se deve, em grande medida, a seguidores de Saikaku. Como escreve o estudioso Donald Keene: "[...] nos trabalhos de Saikaku, o significado da palavra [kôshoku] varia grandemente. Em Um Homem que se Deu ao Amor é galante; em Cinco Mulheres do $A m o r^{6}, k o ̂ s h o k u$ está mais próximo do amor romântico; em Uma Mulher que se Deu ao

- The Lens within the Heart, Nova York, Cambridge University Press, 1996, em estudos sobre o impacto dessas importações no Japão, acentua que os objetos tiveram pouco impacto na ciência japonesa, tendo sido, entretanto, entusiasmadamente difundidos entre os citadinos, primeiramente entre os mais afluentes, que os exibiam como misemono, "coisa para mostrar" Os objetos de precisão (barômetro, termômetro, sextante, balança, relógio) associam-se, como nota argutamente Screech, às representações visuais minuciosas e precisas, sendo ambas saiku.

5. Kôshoku Ichidai Otoko, editada em 1862, é seu primeiro livro em prosa. A narrativa segue a trajetória amorosa de Ukiyo-no-suke, abreviadamente Yonosuke, desde os oito até os sessenta e um anos, tendo sido dividida em cinqüenta e quatro capítulos, segundo a estruturação do Genji Monogatari. Yonosuke, filho de um riquíssimo proprietário de minas e de uma das mais famosas yûjo de seu tempo, goza do amor de formas intensas e variadas. Almejando uma vida galante, Yonosuke não somente freqüenta as grandes artistas do amor das áreas-de-prazeres Yoshiwara, Shimabara, Shinmachi, mas também as serventes do amor de casas de banho, de chá e albergues provinciais; relaciona-se ainda com as mulheres comuns e das "margens dos rios", com os jovens atores do teatro kabuki, wakashu. Durante sessenta e um anos, Yonosuke "se divertiu com 3.742 mulheres e 725 rapazes" de todas as categorias sociais, devido não somente à sua boa aparência física mas, principalmente, ao poder de sua situação econômica. Estudos de Noda Hisao apontam falhas na estruturação do livro, bem como divisões possíveis em três desenvolvimentos: a história de Yonosuke propriamente dita, os catálogos críticos de yûjo e as histórias de província, tendo chegado à hipótese de que manuscritos preexistentes teriam sido juntados e adaptados a um fio condutor, a saber, a vida de Yonosuke. Inovações da pena de Saikaku, no entanto, podem ser notadas: na descrição minuciosa de roupas e alimentos, no comentário elaborado sobre as áreas-de-prazeres, na observação sagaz de seus frequientadores e, principalmente, em transformar em personagens yûjo famosas como Takao, Yoshino, Yûgiri ou Komurasaki. Yonosuke, arrasado pelos gozos e pela decadência física, acaba desaparecendo, num navio, em direção ao "País das Mulheres"

6. Kôshoku Godai Onna trata, segundo o estudioso Abe Jirô, de "paixões de mulheres", mas, segundo Teruoka, de "estranheza do corpo e do caráter de mulheres" A obra mostra os caminhos do amor de cinco mulheres citadinas, amores criminosos segundo as leis do xogunato pois ousam escolher seus amantes, sendo dividida em cinco partes com cinco capítulos cada. Na segunda narrativa, "Osen, a Senhora da Loja de Calendários", Osen se apaixona e se casa, sem que se relate razões sentimentais ou práticas; mais tarde, apaixona-se novamente, mais uma vez, inexplicavelmente. Na verdade, a personagem aprecia o fato de se apaixonar, independentemente do objeto de seu amor, mostrando "uma tendência das mulheres de apreciar o estado de estar apaixonada". A narrativa seguinte gira em torno do amor de uma mulher bem-educada (embora da categoria dos comerciantes) que, na ausência do marido, se deixa enredar numa trama com um servente, numa falta dupla contra os laços do casamento e contra a estratificação social, tendo ambos sofrido uma punição mais severa, a morte por crucifixão. Saikaku expõe um mundo em que, embora seja a mesma a falta, a punição é tanto mais severa quanto mais alto o estrato social do faltoso. Cinco Mulheres do Amor inclui juízos de figuras-bonitas, desta vez não de yûjo mas de citadinas, como se vê na abertura da terceira narrativa; inclui também michi yuki, "caminhada", e pena de morte ocasionada por amores, como se vê amiúde nas peças de Chikamatsu. Diferentemente do amor nas áreas-de-prazeres e de teatro, em Kôshoku Gonin Onna os caminhos do 
Amor, trata-se de desejo puramente físico"7. A ligação de kôshoku do período Edo com irogonomi do período Heian é fundamental para se compreender de que amor se trata: não do amor enquanto algo romântico ou sutil, mas das artes do amor; "galante", "romântico" ou "sensual" não têm pertinência. As artes se ligam, no período Edo, ao kôshoku ("apreciação do sexo"), composto pelos ideogramas gostar-cor. Invertendo-se os ideogramas que compõem kôshoku, respectivamente cor-gostar, se tem iro-gonomu ("gostar-cor"), como em Ise Monogatari: "irogonomu to ifu suki-mono" ("o especialista refinado que é amador do amor"); em Genji Monogatari, há irogonomi e fûryû no konomi. Ou seja, o relacionamento de suki, amador das artes, com o erotismo já se estabelece, incluindo as coisas elegantes, coletivamente apreciadas (fûrŷ̂). Orikuchi Shinobu ${ }^{8}$, rastreando o iro-gonomi na Antigüidade, enfatiza seu caráter religioso, do qual, no entanto, não se excluem kôshoku e tajô (muitos relacionamentos): para o sucesso de seu reino, o imperador desposaria sacerdotisas xintoístas (miko) de cada região, pois atrairia para seu palácio, através delas, as próprias divindades (kami). Rito de prosperidade em seu início, na corte de Heian as relações amorosas se multiplicam relativamente à posição social, sensibilidade, artes.

Iro (cor), como metonímia das coisas do amor e do sexo, associa-se inicialmente aos deuses, pois se veste o vermelho para chamar atenção dos kami nas cerimônias; o trabalho despendido na obtenção dos pigmentos vegetais e minerais é tido como uma oferta às divindades, um modo de homenageá-las; cores são utilizadas somente por monges e miko ou adornam altares. A cor atrai os deuses e, aproximando-os, os seduz com as artes da dança, da música e da poesia.

$\mathrm{Na}$ época de Saikaku, kôshoku não tem conotação negativa - é tratada exaustivamente por pintores e escritores -, como passa a ter posteriormente, devido, em grande parte, a imitadores que transformam o gênero kôshoku-mono em, segundo alguns estudiosos, "quase fria pornografia"9 Certamente a proibição xogunal dos escritos e pinturas kôshoku, datada dos anos 1720, mais de vinte após as mortes de Saikaku e Moronobu, contribui para sua depreciação. Principalmente, exercem juízos negativos sobre os livros kôshoku autores de obras yomihon, "livros-de-ler" ${ }^{10}$, como o rígido

amor jogam com sentimentos e vidas regidas pelas leis do xogunato; é o amor dos amadores yabo, em oposição ao amor dos profissionais, tsûjin, que têm iki. Essas narrativas, como também outras de Saikaku, são criticadas por alguns estudiosos, mais uma vez, pela "falta de caracterização das personagens": Saikaku não esclarece as razões pelas quais as mulheres se apaixonam, o que demonstra as expectativas da crítica em relação à narrativa que se pretende, para ela, "moderna"

7. World Within Wall - Japanese Literature of the Pre-Modern Era, 1600-1867, Nova York, Holt, Rinehart and Winston, 1976, p. 24.

8. Kubota Kiyoshi (org.), Kîwâdo Hyaku Koten Bungaku no Jutsugo-shû (Cem Palavras-Chave da Literatura Clássica), Periódico Koku Bungaku (Literatura Japonesa), volume 7. Tôkyô, Gakutôsha, 1996.

9. Estudiosos japoneses têm utilizado o estrangeirismo porunogurafi (ou, abreviadamente, poruno) no tocante a escritos kôshoku-bon e estampas eróticas ou "pintura-primavera", shunga; entretanto, o sentido de tal vocábulo não tem valor conotativo negativo como no Ocidente.

10. Yomihon se compõem principalmente por histórias de terror, de um "sobrenatural histórico", como os de Ueda Akinari, mantendo-se no nível cultivado dos conhecimentos confucionistas chineses alegorizados por fantasmas e demônios. Takizawa Bakin leva ao extremo didatismo e erudição chinesa em suas narrativas que exploram efeitos fantásticos e nas muitas peripécias de escritos de gênero baixo, 
confucionista Bakin. O desprezo pelos escritos de Saikaku e pelas obras dos pintoresdas-cidades é juízo de samurais a citadinos.

Em Um Homem que se Deu ao Amor, não se deve entender kôshoku como "amor às mulheres", mas como "amor fûrŷ", elegante e refinado. Estudiosos ocidentais compararam inicialmente Yonosuke a Don Juan; entretanto, Yonosuke não engana ou ilude seus parceiros em busca de um número maior de amores, a constância amorosa não é requerida por nenhuma das partes, a personagem é um coadjuvante do amor em seus estágios e cerimônias. Assim como em Episódios de Ise, Yonosuke é um otoko, um homem, mostrado em várias situações de relacionamentos amorosos, na Capital e nas províncias. No conhecimento do "caminho do amor", kôshoku inclui não só o mundo físico e as ações físicas quando se o trilham, mas também seus juízos, de onde se originam as concepções características dos hedonistas citadinos do período Edo: sui, iki, hari, tsû, yabo, hankatsû, tsûjin ${ }^{11}$

No juízo excelente dos caminhos do amor ("nada há superior a uma yûjo ${ }^{12}$ de Kyôto, com o espírito alerta e orgulhoso, hari ${ }^{13}$, de Edo, num ageya ${ }^{14}$ suntuoso de Ôsaka"15), yûjo e clientes de províncias, assim como atores de várias categorias, retomam a discriminação das províncias, já vista em Narihira. Entretanto, no período Edo, as províncias contrapõem-se, não somente à Capital Kyôto, mas também a Ôsaka e Edo, tendo as Três Cidades se tornado objeto de comparações várias, mono-awase ${ }^{16}$.

também nomeados zoku-bungaku, literatura dos comuns. Os autores são escritores profissionais que têm um público certo a ser cativado, pouco importando os meios para tal. Yomihon, "livro-de-ler", geralmente não tem "pintura-introduzida" (sashi-e) e mantém a referência às coisas chinesas. Tsuga Teishô (1718-1794), médico e escritor de Kyôto, confucionista, escreve o primeiro yomihon, composição erudita de chinês e japonês: Kokon Kitan Hanabusa Sôshi (Escritos de Histórias Estranhas do Presente e do Passado). Takebe Ayatari (1719-1774) estuda haikai, kanga (pintura-chinesa), kokugaku (estudos-vernaculares) e escreve yomihon, iniciando com a obra Nishiyama Monogatari um novo caminho, kaidan-goto (histórias-de-fantasmas). Nas narrativas curtas de Ugetsu Monogatari (Contos da Chuva e da Lua), de Ueda Akinari, aparecem fantasmas de vivos e de mortos que são metáforas de desejo, luxúria, maldade, crime, vingança e castigo. Akinari estuda kangaku (estudos-chineses) com Tsuruga Teishô e kokugaku (estudos-vernaculares) com Takebe Ayatari e, no dizer de Katô Shûichi, "dedicou seu pincel ao gênio chinês e aos demônios japoneses"

11. Essas concepções são complexas e permeiam todo o período Edo. Grosso modo, sui seria mais característica do Primeiro Período Edo (1600-1750), tendo se centralizado em Kyôto e Ôsaka; é "charme, sedução, altruísmo" dos habitantes das áreas-de-prazeres. $I k i$, leitura do mesmo ideograma, seria mais característica do Segundo Período, é sua interpretação na cidade de Edo: "charme, sedução, simplicidade, orgulho" dos citadinos. Tsûjin e yabo são atitudes dos freqüentadores das artes do amor, o especialista e o incauto, mediados pelo hankatsû.

12. Mantém-se aqui o termo original yûjo, "mulher-entretenimento", entendendo que a tradução corrente "cortesã" em poucos aspectos se lhe assemelhe.

13. Concepção das áreas-de-prazeres em relação à atitude de yûjo, que devem ter hari: espírito alerta, charme, modo galante, agudo e direto.

14. "Casa de designação", ou casas oficialmente reconhecidas pelo xogunato e controladas por comerciantes, as quais servem de locais de encontros e fruição dos entretenimentos da conversação, dança, música, bebida, comida e amor, entre as yûjo e seus clientes.

15. Kyô no jorô ni, Edo no hari wo motase, Ôsaka no ageya de awaba, kono ue nanika arubeshi, in Kôshoku Ichidai Otoko, VI: 6.

16. Mono-awase é entretenimento da corte do período Heian: "comparação-de-coisas", baseia-se na reunião de nobres que se entretêm em discriminar e julgar as qualidades de objetos semelhantes, como conchas, plantas, aromas, mulheres, bem como compor e julgar caligrafia, pintura, poesia, execução musical. 
Saikaku escreve também histórias de samurais - Relatos de Tradições de Samurais ${ }^{17}$ e Narrativas de Obrigações de Samurais ${ }^{18}$-, baseadas principalmente nas tópicas: honra, vingança e amor de homens. Em algumas narrativas, a busca da vingança é ocasionada por desafios e humilhações à honra do senhor, mas, das trinta e duas narrativas, onze desenham vinganças amorosas. Muitos estudiosos julgam essas narrativas de samurais escassas e superficiais, mostrando um juízo que supõe haver "profundidade" em "escritos-folhas" (sôshi) ${ }^{19}$. Um caso como o que deu origem à peça Kanadehon Chûshingura (A Liga dos Quarenta e Sete Samurais), ocorrido em 1703, após a morte de Saikaku, mostrou-se mais adequado ao pincel de Chikamatsu Monzaemon: o drama trágico, em oposição à sua leveza.

O amor de homens, também kôshoku, é tratado de modo abrangente em relação a samurais, seguindo a tradição, como podemos ler em Nanshoku Ôkagami (O Grande Espelho do Amor de Homens), representando samurais e seus amantes, segundo regras galantes e honoríficas. Os papéis ativo e passivo são exercidos, respectivamente, pelo mais velho (yarô, acima de dezesseis anos) e pelo mais moço (wakashu), numa relação marcada pelo amor-fidelidade confucionista, chû. Na segunda parte, Saikaku enuncia, sobretudo, juízos sobre atores: trata do amor de homens envolvendo atores de kabuki, desnudando seus truques para tirar o máximo proveito de seus amantes. Os dois "mundosseparados", betsu-sekai, do período Edo são as áreas-de-prazeres, onde se praticam as artes do amor entre homens e mulheres, e as áreas-de-teatro, onde se praticam o amor entre homens.

O amor entre samurais enfoca, além da beleza do corpo, a beleza da fidelidade; mais que de amor, trata-se de uma ética regulamentada por giri, obrigação e honra. A associação do amor e da morte, segundo Ueda $\mathrm{Kazuo}^{20}$, é purificadora e signo de sinceridade, lealdade e capacidade de sacrifício; "a morte é o eros". Os triângulos amorosos entre atores e samurais acabam em suicídio, assassínio, violência. Mas, entre os atores, wakashu, a beleza da ética é secundária em relação à beleza do corpo, a qual, sendo efêmera, resulta em relações amorosas efêmeras; sinceridade e lealdade são encenadas, devido a ser pago o amor. Nesse sentido, no engodo, na inconstância e no interesse material, essas relações amorosas se aproximam, pela preponderância do dinheiro, das mantidas com as yûjo, e a morte-juntos (shinjû) adquire um outro valor: a purificação da mundaneidade e a eternização da beleza efêmera se revestem em tópicas cômicas.

Noda Hisao ${ }^{21}$ critica as histórias trágicas de amor entre os samurais, pois, primeiramente, Saikaku se afastaria, para ele, de seu tema, o amor de homens, tratando-

17. Buke Denraiki, de 1687, compõe-se de trinta e duas histórias de vingança de samurais do passado e da época.

18. Buke Giri Monogatari, de 1688, compõe-se de vinte e seis histórias acerca da lealdade dos samurais do passado e da época.

19. Há vários ideogramas para sôshi: "pequena-planta", "pequeno-volume", "papel-planta", "papel-juntado", vocábulo que nomeia o gênero no qual Saikaku escreve, ukiyo-zôshi (sôshi sonorizado).

20. In Saikaku Bungei no Kenkyû (Estudo sobre a Arte da Escrita de Saikaku), Tôkyô, 1980.

21. In Nihon Kinsei Shôsetsu-shi, Ihara Saikaku hen (História do Romance Japonês da Era Moderna Seleção de Ihara Saikaku), Tôkyô, Kyôjôsha, 1989, p. 301. 
o apenas em termos de obrigações e lealdades, sendo suas personagens sempre de beleza ímpar e qualidades indiscutíveis; em segundo lugar, porque todas as histórias, mais uma vez, se passam no passado (também em Kôshoku Ichidai Otoko as yûjo referidas são todas do passado), nas eras Kan'ei (1624-1629) e Kanbun (1661-1673), como reflexo da proibição xogunal de referir samurais. "Todas as histórias mostram a falta de habilidade e a não-familiaridade de Saikaku com o tema, tendo enfocado, não os samurais de seu tempo, mas os samurais do passado, ainda impregnados de uma visão budista" Estudiosos requerem, ao ler as obras de Saikaku, "retrato do tempo presente" e "profundidade", como se fossem mais que construções de símiles, narrativas leves de um mundo evanescente e prazeroso. Ao enfocar narrativas de samurais e atores em seus amores sob uma veia cômica, através dos olhos de um comerciante familiarizado com escritos da tradição e utilizar retóricas antigas virandoas do avesso de modo prolixo, Saikaku inventa histórias para serem lidas por citadinos.

Nanshoku Ôkagami (O Grande Espelho do Amor de Homens) é de 1687, compondo-se de narrativas curtas de amores entre samurais e atores. Assim se inicia o primeiro livro, na defesa do amor de homens ${ }^{22}$ :

\section{I: 1. Amor: a Disputa ENTRe Duas ForÇAS}

No início da Idade dos Deuses, era o amor de meninos.

Os famosos odiadores-de-mulheres ${ }^{23}$ do Japão.

Ensinamentos sobre Registro das Origens do Amor de Homens [Belo Caminho].

No início da Idade dos Deuses, quando estes iluminavam os céus, o deus Kuni-tokotachi $i^{24}$ aprendeu o amor de meninos de um pássaro ${ }^{25}$ que vivia nas margens secas sob a Ponte Flutuante dos $\mathrm{Céus}^{26}$, brotando, assim, seu amor pelo deus Hi-no-chimaru ${ }^{27}$. Mesmo miríades de insetos preferiam a posição do amor de meninos ${ }^{28}$, e o Japão era também chamado "País das Libélulas"29. O deus Susanoo, com a idade, voltou-se à princesa Inada ${ }^{30} \mathrm{e}$, desde então, há parteiras e choros de bebês que berram; megeras velhas intermediárias apareceram; pais começaram

22. A tradução de obras de Saikaku foi baseada na edição Ihara Saikaku-shû (Coleção Ihara Saikaku), com notas e comentários de Teruoka Yasutaka e Higashi Akimasa. Tôkyô, Shôgakkan, 1971.

23. Nihon ni karuremo naki onna-girai no koto: "episódios de odiadores-de-mulheres que não se tem como esconder no Japão".

24. Kuni-toko-tachi-no Mikoto: "deus que se levanta sempre no país", invenção de Saikaku em analogia aos nomes de deuses nas primeiras obras históricas do Japão, Kojiki e Nihon Shoki.

25. Shiribiki, "alvéola", outro nome para sekirei.

26. Ama no Uki-hashi. Margem seca, kawara, faz menção da área ocupada pelos atores de kabuki e yûjo, Shijô-Kawara, na cidade de Kyôto.

27. Hi-no-Chimaru-no Mikoto, "deus dos mil dias", invenção de Saikaku.

28. Jakkei, composto pelos ideogramas waka e chigiri, significa "relações com wakashu"

29. Seireikoku é leitura chinesa para Akitsu-no Kuni, "País das Libélulas" ou, com outros ideogramas, "País da Baía de Outono"

30. Na Idade dos Deuses, Susanoo é casado com Kushitada-hime, "Princesa dos Campos de Arroz", o mesmo ideograma usado por Saikaku, mas lido diferentemente. 
a sofrer com a longa espera e o peso do dote de suas filhas. Por que, quando não há forma de entretenimento mais belo do que o amor de homens, as pessoas de hoje ignoram seus sutis prazeres?

Pois, é profundo o amor de meninos, havendo casos numerosos tanto na história da China quanto na do Japão. Wei Ling-kung confiou sua vida a Mi Tzu-hsia, Kao Tsu entregou seu coração a Chi Ju, Wu Ti dividia seu travesseiro somente com Li Yen-nien. Em nosso país, também, o "homem de antigamente" 31 foi, por mais de cinco anos, 0 amigo devotíssimo ${ }^{32}$ do irmão mais novo de Ise, Daimon-no Chûjô ${ }^{33}$. Durante aqueles cinco anos, houve primaveras sem que [o "homem de antigamente"] visse flores; esqueceu-se das luas de outonos; carregou neves de sofrimentos sem explicação; encheu de tempestades suas mangas; atravessou pontes de gelo;

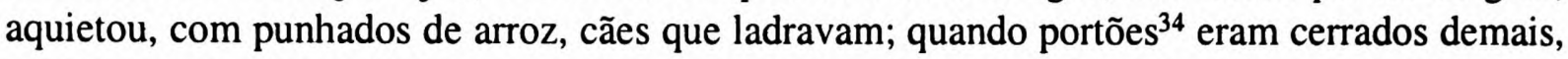
entrava com a chave do ocultamento; mesmo na escuridão amaldiçoava a floresta de estrelas e praguejava contra o brilho de vagalumes [que o mostravam]; com serventes que se refrescavam, ele se sentava com seu amado [Chûjô]; suas pernas se tingiam do sangue de pernilongos, mas, mesmo assim, ele não desistia e lamentava o amanhecer; os cabelos [do "homem de antigamente"] se embaraçavam com o vento; a separação anunciada pelo pássaro que marca as horas o fazia verter lágrimas da chuva que não caía; captava-as logo no tinteiro ${ }^{35} \mathrm{e}$, transportando o seu coração para o pincel, escrevia um rolo sobre aqueles dias, intitulado Coleção das Visitas Noturnas ${ }^{36}$. Como é que ele voltou as costas para o amor de homens e se pôs a fazer narrativas sobre mulheres? ${ }^{37}$ Depois de sua maioridade ${ }^{38}$, ele abandonou seu impossível amigo devotíssimo e partiu para a capital Nara e o lenço da jovem Púrpura ${ }^{39}$ o tornou o ancestral de todos os atores adultos [yarô] de kabuki. De costas, tinha a aparência de uma linda flor de pessegueiro ${ }^{40}$ que se esquece de ferir ou de galhos do salgueiro balançando ao vento. Mao Ch'iang e Hsi Shih ${ }^{41}$, com certeza, se envergonhariam. Mesmo depois da maioridade, Narihira ainda preferia a companhia de belos jovens; o fato de ser chamado Deus do Yin e Yang do Mundo Flutuante ${ }^{42}$ deve causar-lhe vexação, [agora que se encontra] nas sombras de folhas e árvores ${ }^{43}$. Um outro exemplo é o monge Yoshida Kenkô; ter enviado milhares de cartas de amor a Kiyo-Wakamaru ${ }^{44}$, sobrinho de Sei Shônagon, todos perdoam, mas, por causa da única carta de amor para uma mulher que ele

31. Mukashi otoko, refere-se a Ariwara Narihira, a quem já foi atribuída a autoria de Ise Monogatari.

32. Nen'yû, "amigo de devoção", refere parceiros do amor de homens.

33. Ise é poeta dama da corte de Heian, uma das Trinta e Seis Poetas Imortais. Não se conhece Daimon-no Chûjô.

34. Ana mon, "buraco-portão", portões baixos e pequenos em paredes de barro.

35. Suzuri, pedra retangular com leve inclinação para dissolver tinta sumi.

36. Tsûtaishû, livro de memórias; obra inexistente.

37. Refere-se a Ise Monogatari.

38. O primeiro episódio de Ise Monogatari mostra otoko, um homem, indo visitar Nara, a antiga Capital, após sua cerimônia de maioridade.

39. Lenço usado para esconder a parte raspada das cabeças de atores adultos que fazem papéis femininos. O "púrpura jovem" é tecido púrpura e referência à jovem para a qual otoko compõe seu poema.

40. Yôtô, "pessegueiro oculto", referência a uma obra do tempo de Saikaku, Shin'yûki (Relatos de Coraऽões Amigos).

41. Môshô e Seishi, como são chamadas no Japão, são famosas mulheres-bonitas da história chinesa.

42. Ukiyo ni In'yô no Kami: sendo yin e yang as duas forças, por analogia, Narihira seria o "deus dos amores entre homens e mulheres"

43. Quer dizer, "agora que está enterrado sob folhas e árvores"

44. Kiyo-Wakamaru, "jovem puro", é invenção de Saikaku, utilizando-se do primeiro ideograma (Kiyo) do nome de Sei Shônagon (Sei). Shônagon, note-se, é do período Heian e Kenkô, do período Kamakura. 
escreveu a pedidos [de um amigo], seu nome ficou manchado até no outro mundo. $\mathrm{O}$ amor de mulheres é mesmo um caminho que todos os homens devem temer.

Quando recebi a vida, se tivesse a inteligência de hoje, nunca teria sugado os seios de uma mulher. Há, afinal, vários exemplos em que crianças foram criadas com papas e caldos doces.

De qualquer forma, montei minha casa de homens e decidi-me por uma propriedade alugada numa área remota de Asakusa em Edo, na província de Musashi; não me importavam as alegrias e os sofrimentos do mundo ou a paz e a guerra dos homens; sempre trancava os portões; antes da refeição da manhã, já me dedicava ao Registro das Origens do Amor de Meninos ${ }^{45}$; coletei e escrevi sobre, sem exceção, todos os prazeres do amor de meninos - pelos quais temos de agradecer -, que, em meus quarenta e dois anos de viagens pelas províncias vi, ouvi, senti e aprendi.

Primeiro, discriminemos o amor de homens e o amor de mulheres ${ }^{46}$.

O que é preferível:

Uma garota de onze ou doze anos analisando-se de frente e de costas, ou um menino da mesma idade limpando seus dentes?

O leito em que se é rejeitado por uma yûjo, ou a conversa íntima com um menino de kabuki que tem hemorróidas?

Ficar cuidando de uma esposa que sofre do pulmão, ou ter, às vezes, um wakashu que pede coisas ? $^{47}$

Caírem relâmpagos do Deus-das-Águas ${ }^{48}$ no quarto onde se brinca com um menino que se comprou $^{49}$, ou receber uma navalha de uma yûjo que mal se conhece e que lhe pede para morrer com ela?

Perder no jogo e, no dia seguinte, enlouquecer com uma yûjo kakoi de quinze momme $e^{50}$, ou comprar mercadorias quando o preço abaixa e comprar um menino de viagem $?^{51}$

Casar-se com a filha de seu senhor, dormir cedo e ir emagrecendo, ou se apaixonar pelo filho de seu senhor e ver seu rosto apenas durante o dia?

Uma viúva com mais de sessenta anos com um quimono de baixo carmesim contando sua prata, ou um menino com somente as têmporas raspadas ${ }^{52}$ num quimono simples de algodão lendo suas juras passadas de amor?

Frequientar Shimabara demais e perder sua casa hipotecada ${ }^{53}$, ou ensandecer-se demais por Dôtonbori e descobrir que a data de vencimento do empréstimo para o arroz ${ }^{54}$ se aproxima rapidamente?

45. Jakudô Kongen-ki, obra inexistente.

46. Saikaku inicia, a partir daí, a comparação entre os amores; trata-se de mono-awase, juízos sobre coisas semelhantes, que é corrente no período Heian.

47. Mushin iwaruru wakashu, embora não esteja explícito, algumas traduções determinam o que pedem os wakashu: "ter um wakashu que pede dinheiro constantemente para gastar".

48. Mizu-gami-nari, trocadilho para mizu-kaminari, "trovão de água", em oposição a hi-kaminari, "trovão de fogo".

49. Kodomo-kau, "comprar crianças", o menino é ator de kabuki, mas ainda não wakashu.

50. Kakoi é categoria inferior de yûjo, abaixo de tayû e tenjin; como seu preço é fixado em quinze momme, Saikaku grafa o ideograma jûgo, "quinze", mas o faz ler como kakoi.

51. Tobiko, "menino que pula", ou takiko, "menino que viaja", são wakashu que viajam pelas províncias vendendo-se.

52. Sumi-maegami. A maioridade (genpuku) é significada pela raspagem dos cabelos nas frontes; o menino, tendo apenas uma parte raspada (han-genpuku), não atingiu ainda a maioridade.

53. Iejichi, dívida que tem como garantia a residência.

54. Gojômai, "arroz dos castelos", o arroz (imposto xogunal) vinha de todas as províncias (castelos), sendo armazenado em Ôsaka e levado a Edo; era a base monetária do início do período. 
Aparecer o fantasma de um wakashu quando se entretém com Cem Narrativas Medonhas ${ }^{55}$, ou voltar sua antiga esposa pedindo dinheiro?

Espiar sob chapéus de palha quando eles voltam do teatro, ou perguntar a uma aprendiz [kamuro] o grau da yûjo que desfila [dôchû] ${ }^{56}$

Tornar-se atendente de um monge no monte Kôya ${ }^{57}$, ou tornar-se concubina ${ }^{58}$ de um nobre aposentado?

Uma dançarina de templos ${ }^{59}$ que sai a benzer potes de arroz mas coloca seu coração apenas em casas de homens, ou um menino que anda vendendo óleo de sândalo ${ }^{60}$ e que se desagrada da câmara central da residência de um daimio ?61

A boca de uma mulher que tem os dentes pretos, ou a mão de um wakashu que arranca seus pêlos?

Esperar parar a chuva no portal de uma casa-de-designação que não se conhece, ou ter-lhe recusada uma lanterna na escuridão, quando se volta dos aposentos de um menino? ${ }^{62}$

Conhecer os sons de uma garota de casa-de-banhos, ou visitar secretamente um wakashu em contrato-de-trinta-dias [com outro homem]?

Patrocinar uma yûjo, ou comprar uma casa para um ator de kabuki [yarô]?

Emprestar seu agasalho para um tambor [taiko] de Yoshiwara ${ }^{63}$, ou dar algumas moedas a um atendente de ator na margem do rio? ${ }^{64}$

Ir para Shinmachi antes da Festividade Bon e apaixonar-se por uma yûjo, ou enamorar-se de um ator antes da Primeira Apresentação Anual ${ }^{65}$ no palco?

Uma mulher de casa-de-chá mastigando nozes, ou um wakashu vendendo aromas que brinca com sua balança?

Observar por trás o penteado de um tayû de kabuki ${ }^{66}$ quando ele entretem num barco ${ }^{67}$, ou ver de frente uma esposa em quimono kanoko numa carruagem de mulher voltando da apreciação de flores de cerejeira?

55. Hyaku Monogatari, Cem Narrativas, é diversão apreciada nas noites de verão: cem lanternas acesas são apagadas à medida que os participantes contam narrativas de fantasmas (kaidan).

56. A ação é típica de yabo.

57. Segundo provérbio "Kôya, sessenta; Dachi, oitenta" Nos templos das montanhas Kôya e Dachi, era proibida a presença de mulheres, portanto, mesmo envelhecendo, os homens eram sempre tratados como wakashu.

58. Tegakemono, "pessoa que cuida", são esposas secundárias, concubinas; em Kansai se chamava tekake, em Kantô, mekake.

59. Miko. Em determinado dia de cada mês as miko visitavam as casas e purificavam os potes de arroz (kama barai); em Kôshoku Ichidai Otoko, livro III, episódio 7, há miko que vendem sexo.

60. Kyara no abura, um dos tipos de óleo para cabelo de penteados de homens; é vendido por meninos ambulantes.

61. Chûgen beya, diz-se dos quartos de residências (yashiki) de daimio hatamoto, samurais principais do xogunato, os quais, dizia-se, eram pródigos amantes.

62. Kodomo yado, aposento em que os atores de kabuki recebem seus visitantes.

63. Não se trata de Yoshiwara da cidade de Edo, mas de região de área-de-prazeres Shinmachi, de Ôsaka, contando com duas casas-de-designação (ageya) apenas de yûjo kakoi de baixa categoria.

64. Kawara, refere-se a Shijô-Kawara de Kyôto.

65. Kaomise, "mostrar as faces", refere-se a evento que ocorre todos os anos em todas as companhias de teatro para mostrar o repertório do ano e as novas faces dos atores.

66. Tayû ko, o primeiro ator, o número um dos atores onnagata das companhias ( $z a)$ de teatro.

67. Kawa goza (fune), barco de divertimentos, com cobertura. 
Um jovenzinho de calças e quimono curto que caminha com seu atendente carregando seus livros, ou uma empregada vestida languidamente que caminha com sua ajudante carregando uma caixa de cartas laqueada segundo a moda? ${ }^{68}$

Um servente favorito de um daimio sentado na grande sala de recepção, ou a figura desalinhada de uma dama de pé nos aposentos femininos do palácio?

Ser zombado por enviar uma carta de amor para um wakashu de mangas presas ${ }^{69}$, ou ser olhado com suspeita quando desperta interesse em uma mulher em quimono de mangas longas?

Se formos eleger um dos dois caminhos, mesmo que a mulher seja uma beleza e de disposição gentil e mesmo que o wakashu seja desagradável e de nariz repulsivo, é um sacrilégio dizer que o amor de mulheres tem o mesmo nível que o amor de meninos.

O coração da mulher, se formos comparar, embora nele floresçam glicínias, tem galhos retorcidos. $\mathrm{O}$ wakashu, mesmo tendo espinhos, é como o primeiro botão de ameixeira que exala um aroma indescritível. A única escolha sensata é abandonar as mulheres e se voltar aos homens. A razão pela qual Kôbô Daishi [o grande monge] não pregou os aspectos nada frívolos desse caminho foi que ele, lamentando as sementes humanas, via o caminho dos homens extinguindo o mundo. Quando este se espalhasse, a vida seria desertada. Por que será que o "homem amoroso"70 desperdiçou quantidades de ouro e prata em sua miríade de mulheres? O máximo prazer só é possível no amor de homens. Escrevi neste Grande Espelho copiando todas as figuras [do amor dos homens], sem deixar escoá-las, como algas coletadas nas redes ${ }^{71}$ da estreita baía de Naniwa; como as plantas em cada rede, em cada ouvido estas folhas passarão e neste mundo se escoarão ${ }^{72}$.

Na referência ao antigo otoko, Narihira, esse episódio atinge proporções paródicas; modoki, "tomar como modelo (os antigos)" e yatsushi, "disfarçar-se"73, são técnicas utilizadas para transformar Narihira, de "deus do amor de homens e mulheres", a "deus do amor de homens" Narihira, o poeta nunca denominado mas sempre inferido pelo leitor, o praticante de uma variedade de amores e poemas na obra anônima do período Heian, Ise Monogatari, é retomado no período Edo não somente por Saikaku: também

68. Jidai maki-e bako, trata-se de caixa laqueada com incrustações, da época Higashiyama.

69. Waki fusagitaru, os wakashu, após a maioridade, raspam o topo da cabeça, como se viu, e vestem mangas presas aos punhos. Após a maioridade, tornam-se anibun, "papel de irmão-mais-velho", papel ativo.

70. Kôshoku Ichidai Otoko.

71. Moshio-gusa, rede usada no mar para tirar sal. É trazido foneticamente por kaki atsumeru, "escrever e juntar, coletar", da frase anterior e kaki atsumeru, grafado com outro ideograma, "coletar folhas, juntar dinheiro", associado a poema em Shinzoku Kokin (Novo Kokin Continuado).

72. Kataha no ashi no kata mimi ni; kore mina kiki nagashi no yo ya. Frase complexa de traduzir: kataha, "cada folha", é procedimento utilizado em Ôsaka, Fushimi, Uji e outros locais, para fazer a água escoar usando-se apenas uma das redes (katappô no ha); katamimi, "um só ouvido", significa ouvir casualmente, ouvir histórias leves. Segundo a versão para língua moderna de Teruoka: "[...] mas, como são, afinal, histórias que se ouvem casualmente, é natural que elas sejam ouvidas e esquecidas".

73. Yatsusu - fazer com que algo se torne mais pobre, miserável, tímido (misuborashii yô ni suru), mudar seu aspecto visual de modo a não chamar atenção (metatanu yô ni sugata wo kaeru), abreviar, reduzir as coisas (monogoto wo shôryaku suru) - revela, em seu processo de disfarce, a sua outra natureza. Mais conhecida como técnica na construção da trama do teatro kabuki, yatsushi-goto refere-se à recorrente situação de um personagem elevado (nobre, daimio, samurai) levado a se disfarçar em samurai inferior ou simples citadino para descobrir mazelas de outros personagens. $O$ disfarce, por evidente que seja, é sempre bem-sucedido, e o momento da revelação do personagem, sempre um clímax. 
nas pinturas apreciadas pelos "exuberantes comerciantes das cidades", gôka machish $\hat{u}$, feitas principalmente por Tawaraya Sôtatsu, Ogata Kôrin, Ogata Kenzan ${ }^{74}$, as tópicas das Narrativas de Ise são retomadas e transformadas.

Ao disfarce, yatsushi, se liga mitate, "ver-erguer" Se o disfarce visa apagar a identidade, mitate explora a convenção da dupla identidade. Mitate, sendo essencialmente uma técnica visual (é também utilizada por escritores), evoca dualidades em suas imagens: trabalhada por muitos artistas ukiyo-e, a identificação de yûjo com damas da corte de Heian é convenção que perpassa os dois períodos; já se pode encontrá-la satiricamente em Saikaku. Mitate demonstra que o conceito de pintura como humilde imitação da pintura antiga prevalece; mitate-e, pintura metafórica, transfigura obras antigas, delas se aproximando de modos variados: leve, irônico, paródico, mas também didático, solene, trágico.

Mitate pode ser compreendido também como o emprego da paródia, tendo sido freqüente no ukiyo-e, quando os aspectos mais sagrados das três religiões e os mitos mais cultuados da história são transformados em análogos burlescos no "mundo flutuante". ora sutil ora hilariamente e, às vezes, com uma obscuridade que desafia a interpretação das faltas de conhecimento de escritos e pinturas da tradição e do momento presente.

Assim se compreende a interpretação de Parinirvana de Buda, em uma pintura em rolo vertical de Hanabusa Itchô ${ }^{75}$, em que Buda é substituído pelo poeta Narihira; em outra de suas pinturas, Buda é uma yûjo velada por habitantes e freqüentadores de áreas-de-prazeres. Assim se compreende também a pintura em suiboku, preto-e-branco, de Ito Jakuchû ${ }^{76}$, em que Buda é substituído por um nabo (Daikon Nehan).

74. Também chamada de Sôtatsu-Kôrin-ha, a "correnteza Kôrin", Rinpa, tem características muito diferentes das das outras famílias artísticas por consangüinidade ou adoção, tendo-se formado a partir de afinidades pictóricas, e não em sistema piramidal familiar iemoto: entre Tawaraya Sôtatsu (?-1643?) e Ogata Kôrin (1658-1716) há um intervalo de uma geração, e mais de cem anos são necessários para a emergência de Hôitsu (1761-1828), que se associa a eles, embora houvessem existido outros nesse ínterim, menos proeminentes. A relação entre Sôtatsu e Kôrin se torna possível graças à mediação de parentesco entre ambos com membros da família Hon'ami, linhagem de Kôetsu (1558-1637). Hôitsu, por sua vez, toma contato com a obra de Kôrin através da grande coleção de sua família, que havia sido sua patrocinadora, cinco gerações antes. Durante o período Edo, a obra de Sôtatsu é pouco conhecida, sendo apreciados, no entanto, os abanicos (uchiwa) que fabrica: Tawaraya é o nome de sua oficina de leques; trata-se, portanto, de um citadino, manufatureiro-comerciante. É redescoberto no período Taisho (1912-1926) e reconhecido como o introdutor da utilização de pós e pigmentos dourados e prateados e da folheação de ouro em desenhos e pinturas, mérito atribuído anteriormente a Hon'ami Kôetsu, artista que o ofusca, à época, devido aos múltiplos talentos que possui (de ceramista, notável calígrafo, mestre de chá e de dança-canto utai, laqueador, especialista em juízos de espadas).

75. Itchô (1652-1724) se situa entre os modos ukiyo-e e kanô, tendo pintado figuras-bonitas de Yoshiwara, cenas urbanas, cantores; foi também poeta, tendo aprendido haiku com o amigo Bashô.

76. De acordo com documento encontrado no verso da pintura, diz-se que o rolo era tesouro do templo Emmeiji em Ise. Consiste na narrativa de Pari-Nirvana de Shakyamuni, descrito no texto Mahâyâna. Restam mais de quarenta pinturas, muitas delas designadas como jûyô bunkazai (propriedade cultural importante), contendo muitos elementos sincréticos derivados de mais de uma fonte textual. In Shimizu Yoshiaki, "Multiple Commemmorations: The Vegetable Nehan of Itô Jakuchû". In Sanford, Lafleur \& Nagatomi (eds.), Flowing Traces - Buddhism in the Literary and Visual Arts of Japan, Nova Jérsei, Princeton University Press, 1990, p. 202. 
Mitate se aproxima de mono-awase, "comparação de coisas" do período Heian, segundo alguns teóricos de literatura, pois, na aproximação de "coisas" diferentes passase necessariamente pela comparação. A maior parte dos estudiosos, principalmente ocidentais, traduz mitate como "paródia" (termo que, por sua vez, é reintroduzido no japonês como estrangeirismo: parodi). Talvez haja, de fato, um aspecto do riso em se fazer, de yûjo, damas de Heian ou de nabos, Buda; o riso (warai) do período Edo está ainda pouco estudado devido à dificuldade de compreensão das referências de seus trocadilhos. Entretanto, se é risível yûjo adotarem nomes (também compreendidos como gô) Yûgao ou Murasaki ou Yûgiri ${ }^{77}$, nas pinturas de Jakuchû e de Itchô, que também empregam mitate, o riso cede lugar à reverência: yûjo sendo choradas como mitate nas cenas da morte de Buda evidenciam, como diz a personagem Ichidai Onna de Saikaku: "mesmo que eu tenha vivido neste mundo flutuando desse modo [como yûjo], tenho certeza de que meu coração não se turvou". É a reverência da flor-de-lótus, que do lodo se ergue, branquíssima.

Talvez se possa, também, associar mitate a honka-dori, alusão a poemas da tradição dos nobres de Heian, pois necessariamente se associam as "coisas" do passado (Heian ou Kamakura) às do presente (Edo). Se, entretanto, em Saikaku sobra irreverência (Narihira é feito deus do amor de homens, Ono-no Komachi é feita esposa de fabricante de calendários, Yoshida Kenkô é feito amante do sobrinho de Sei Shônagon, o primeiro amor de deuses é de homens), em Akinari só há reverência a antigos generais chineses, à ética confucionista, a fantasmas, como aparecem em Ugetsu Monogatari (Narrativas da Lua e da Chuva). Há, portanto, em mitate, relação entre kotoba (passado) e kokoro (presente): "a palavra é antiga, o coração é novo"78.

As comparações, mono-awase, entre o amor de homens e mulheres e o amor de homens atualizam o entretenimento corrente da nobreza de Heian, tornado entretenimento de citadinos, trazendo elementos de seu tempo, sempre do âmbito das cidades: diferentes categorias de yûjo das áreas-de-prazeres e de wakashu do teatro kabuki, estilos de penteados e quimonos, samurais disfarçados, festivais, serventes, casas comerciais, moedas, hipotecas, empréstimos. O recurso é amiúde utilizado por Saikaku, juntamente com tropos e tópicas poéticas da tradição, sempre torcidas ao sabor citadino da era Genroku.

A auto-referência através de Kôshoku Ichidai Otoko é irônica, dialogando com seu leitor, que, assim persuadido dos méritos do amor de homens, inicia-se na leitura dos casos amorosos entre samurais e atores de teatro, guiado pela voz de um narradorcomerciante disfarçado de retirado-do-mundo em uma "casa de homens", numa "propriedade alugada numa área remota de Asakusa em Edo, na província de Musashi”".

77. Os nomes de personagens de Narrativas de Genji são muito usados pelas yûjo.

78. Um dos preceitos poéticos mais permanentes na composição de waka, poema japonês, em que se entende que o repertório poético ou a dicção poética (kotoba) provêm da tradição, mas sempre para expressar novos conteúdos, sentimentos e sensibilidade (kokoro). Veja-se tradução e estudo de Geny Wakisaka sobre o prefácio de Ki-no Tsurayuki para a coletânea imperial Kokin Wakashû, in Estudos Japoneses 17, São Paulo, CEJ-USP, 1996. 


\section{Bibliografia}

KATÔ, Shûichi. A History of Japanese Literature - The Years of Isolation, volume 2. Tradução de Don Sanderson. Tôkyô, New York e San Francisco, Kôdansha, 1983.

KEENE, Donald. World Within Wall - Japanese Literature of the Pre-Modern Era, 1600-1867. Nova Iorque, Holt, Rinehart and Winston, 1976.

TSUDA, Sôkichi. An Inquiriy into the Japanese Mind as Mirrored in Literature - The Flowering Period of Common People Literature. Tradução de Matsuda Fukumatsu. Nova Iorque, Connecticut \& Londres, Greenwood Press, 1988 ( $1^{a}$ edição 1970).

LANE, Richard. Saikaku: Novelist of the Japanese Renaissance. Michigan, University Microfilms, tese de doutorado não publicada, 1957.

"Saikaku's Contemporaries and Followers, The Ukiyo-zôshi 1680-1780". In Monumenta Nipponica XIV 3-4. Tôkyô, Sophia University, 1958-59, pp. 125-137.

"Saikaku and the Japanese Novel of Realism". In Japan Quaterly. IV, 2, Abril-Junho. Tôkyô, Sophia University, 1957, pp. 178-188.

"Saikaku's Prose Work, a Bibliographical Study" In Monumenta Niponica XIV, 1-2. Tôkyô, Sophia University, 1958, pp. 1-26.

MATHERS, E. Powys (trad.). Ihara Saikaku - Gay Tales of the Samurai. São Francisco, Alamo Square Press, 1995.

(trad.). Saikaku Ihara - Comrade Loves of the Samurai. Tôkyô, Charles E. Tuttle Co., 1972.

MATSUDA, Osamu (intr., tradução para o japonês moderno, notas). Shinchô Nihon Koten Shûsei 48. Kôshoku Ichidai Otoko (Coleção de Literatura Clássica Japonesa da Editora Shinchô 48. Um Homem que se Deu ao Amor). Tôkyô, Shinchôsha, 1982.

MORRIS, Ivan (trad., prefácio). The Life of an Amorous Woman - and Other Writing by Ihara Saikaku. Nova Iorque, Coleção Unesco de Obras Literárias Representativas, A New Directions Book, 1963.

NoDA, Hisao. Nihon Kinsei Shôsetsu-shi, Ihara Saikaku hen (História do Romance Japonês da Era Moderna - Seleção de Ihara Saikaku). Tôkyô, Kyôjôsha, 1989.

SCHALOw, Paul Gordon (trad., notas, prefácio). The Great Mirror of Male Love - Ihara Saikaku's Nanshoku Ôkagami. Califórnia, Stanford University Press, 1990.

TERUOKA, Yasutaka \& HigASHI, Akimasa (eds.). Nihon Koten Bungaku Zenshû, Ihara Saikaku vols. 1 e 2 (Coleção Literatura Clássica Japonesa, Ihara Saikaku, vols. 1 e 2). Tôkyô, Shôgakkan, 1971.

(intr., notas). Gendaigo-yaku Saikaku Zenshû 1. Kôshoku Ichidai Otoko (Coleção Traduzida para o Japonês Moderno Saikaku 1. Um Homem que se Deu ao Amor). Tôkyô, Shôgakkan, 1976.

. Kôshoku-mono no Sekai (O Mundo dos Escritos Kôshoku). Tôkyô, NHK Bukkusu, 1980.

UEDA, Kazuo. Saikaku Bungei no Kenkyû (Estudo sobre a Arte da Escrita de Saikaku). Tôkyô, 1980.

YoSHIE, Hisaya. Saikaku Bungaku to Sono Shûhen (A Literatura de Saikaku e seus Contemporâneos). Tôkyô, Shitensha, 1990. 